\title{
Mediastinal Hodgkin Lymphoma
}

National Cancer Institute

\section{Source}

National Cancer Institute. Mediastinal Hodgkin Lymphoma. NCI Thesaurus. Code C6634.

A Hodgkin lymphoma that arises from the mediastinum. It usually involves mediastinal lymph nodes and/or the thymus. Signs and symptoms include fever, weight loss, fatigue, and night sweats. 